Nataša L. Janićijević ${ }^{*}$

https://doi.org/10.18485/analiff.2020.32.1.17

Univerzitet u Beogradu

$811.131 .1^{\prime} 366.584$

Filološki fakultet

$811.163 .41^{\prime} 366.584$

Originalni naučni rad

Primljen: 27.04.2020.

Prihvaćen: 13.07.2020.

\title{
IZRAŽAVANJE ANTERIORNE BUDUĆE RADNJE U ITALIJANSKOM I SRPSKOM JEZIKU
}

U radu se opisuju i porede glagolski oblici kojima se u italijanskom i srpskom jeziku izražavaju radnje koje su na vremenskoj osi smeštene posteriorno u odnosu na trenutak govora, a anteriorno u odnosu na drugu buduću radnju. Cilj rada jeste da se utvrde njihove međusobne sličnosti i razlikei da se ustanovi u kojoj meriitalijanski i srpski ispoljavaju podudarnosti i razlike u pogleduizražavanja anteriorne buduće radnje.Rezultati sprovedene kontrastivne analize pokazuju da se između italijanskih i srpskih glagolskih oblika kao markera za anteriornu buduću radnju javljaju kako apsolutna i delimična poklapanja, tako i brojne razlike. Ove tri vrste odnosa manifestuju sepre svega na morfosintaksičkom planu, a ogledaju se u postojanju odnosno nepostojanju nekih formalno istih sredstava za obeležavanje anteriorne buduće radnje, kao i u njihovoj sintaksičkoj distribuciji.

Ključne reči: italijanski, srpski,anteriorni futur, prost futur, futur I, futur II, perfektivni prezent, složeni perfekat, perfekat, ekvivalenti.

\section{Uvod}

I italijanski i srpski jezik u svom glagolskom sistemuposeduju oblik čija je osnovna funkcija izražavanje budućih radnjikoje su na vremenskoj osi smeštene posteriorno $u$ odnosu na trenutak govora, a anteriorno u odnosu na drugu buduću radnju. U italijanskom jeziku tu funkciju obavlja anteriorni futur (it. futuro anteriore), a u srpskomfutur II, koji, u odnosu na anteriorni futur,ima širi raspon upotreba jer može da označava i radnju koja je istovremena s drugom budućom radnjom, kaoiradnju koja je posteriorna u odnosu na nju. Uz to, za razliku od anteriornog futura, futur II može izražavati i radnje koje se su posteriorne u odnosu na neku prošlu radnju a anteriorne $\mathrm{u}$ odnosu na trenutak govora i pripadaju planu prošlosti.

Osim ova dva oblika, u oba jezika, a pre svega u italijanskom, postoje i druga glagolska vremenakoja, van svojih osnovnih upotreba, u odgo-

* natasa.janicijevic@fil.bg.ac.rs 
varajućim sintaksičko-semantičkim okolnostimamogu obavljati funkciju izražavanja anteriornih budućih radnji.U ovom radu pažnja se posvećuje upravo glagolskim oblicima kojima se u dvama jezicima mogu izrazitiradnje koje su buduće u odnosu na trenutak govora, a prošle u odnosu na drugu buduću radnju; ne uzimaju se u razmatranje radnje koje su smeštene posteriorno u odnosu na referencijalnu tačku u prošlosti. ${ }^{1}$ Cilj ovog rada jeste da se opišu i porede različitasredstva za iskazivanje anteriorne buduće radnje u italijanskom i srpskom jeziku i da se utvrde i opišusličnosti i razlike između njih.

Jezička građa za ovo istraživanjesastoji seprvenstveno od primera preuzetihiz korpusa Coris Univerziteta u Bolonji i Korpusa savremenog srpskog jezika (Kssj) Univerziteta u Beogradu. Uz to, imajući u vidu činjenicu dagramatike sveobuhvatno $i$ iscrpno obrađuju upotrebe glagolskih vremena i da za te upotrebe navode odgovarajuće primere, u ovom radu smo se opredelili da takve primere preuzmemo upravo iz gramatika, s ciljem da dokumentovano ilustrujemo i one upotrebe analiziranih glagolskih vremena koje nisu zastupljene u konsultovanim korpusima, što zbog ograničenosti samih korpusa, ${ }^{2}$ što zbog činjenice da su neke upotrebe glagolskih vremena manje zastupljene u jeziku.Srpski ekvivalenti italijanskih primera i, obrnuto, italijanski ekvivalenti srpskih primera su naš prevod. Za one upotrebe glagolskih oblika koje se u italijanskom i srpskom poklapaju, primere ćemo navoditi samo na italijanskom jer smatramo da je prevod dovoljan i da bismo navođenjem primera i na srpskom nepotrebno duplirali broj primera koji ilustruju istu pojavu.

1 Za razliku od srpskog jezika, u kome ista glagolska vremena označavaju kako buduću radnju koja je posteriorna u odnosu na trenutak govora, tako i onu koja je posteriorna u odnosu na neku prošlu radnju, u italijanskom se, u skladu sa pravilima o slaganju vremena, koriste posebna vremena i načini.

2 Korpus Coris daje maksimalno 1000 rezultata po upitu. Kada se, na primer, pretražuje glagol u složenom perfektu, koji je vrlo frekventno vreme u italijanskom jeziku, svih 1000 rezultata prikazuju njegovu osnovnu upotrebu - upućivanje na (blisku) prošlu radnju.Zahvaljujući dodatnim parametrima u pretrazi, poput vremenskih veznikaappena ‘čim' i dopo che 'nakon što', moguće je pronaći primere sa složenim perfektom u funkciji anteriornog futura u vremenskoj rečenici, ali se, zbog ograničenog broja rezultata, ne mogu pronaći primeri sa složenim perfektom u značenju anteriorne buduće radnje u drugim vrstama rečenice poput, na primer, relativne ili dopunske, koje su uvedene relativnom zamenicom che koji/a/e', odnosno komplementizatorom che da'. 


\section{Anteriorni futur u italijanskom jeziku - Futur II u srpskom}

Kako smo već istakli, u italijanskom jeziku osnovnioblik za označavanje radnje koja će se izvršiti u budućnosti pre neke druge buduće radnje jeste anteriorni futur ${ }^{3}$.Ovaj glagolski oblik spada u perfektivna vremena $i$, uz svoje prototipično upućivanje na anteriornu buduću radnju, odlikuje se i semantičkom komponentom rezultativnosti. Njime se, naime,izražava svršena buduća radnja čiji je rezultat aktuelan u trenutku (iz)vršenja neke druge buduće radnje ili u nekom drugomtrenutku u budućnosti. ${ }^{4}$ Njegova sintaksička distribucija ostvaruje se prvenstveno u vremenskim rečenicama. U upravnoj rečenici, prema čijoj radnji se orijentiše, mogu da stoje prost futur, prezent, imperativ i kondicional sadašnji.Naredni primeri ilustruju upotrebu ovog italijanskog glagolskog oblika u vremenskoj rečenici:

(1) D'accordo, mi arrabbierò dopo che avremo parlato. (Coris: MON2008_10)

'Važi, naljutiću se nakon što budemo razgovarali/razgovaramo.'

(2) Lo (il cellulare) accenda solo dopo che avrà passato la frontiera. (Coris: MON2008_10)

'Upalite ga (mobilni) tek nakon što budete prešli/pređete granicu.'

(3) Appena avrò guadagnato abbastanza soldi per venire a Bruxelles, verrò. (Coris: NARRATTrVaria)

'Čim budem zaradio/zaradim dovoljno novca da dođem u Brisel, doći ću.'

(4) Quando avranno smesso di cercarci, torneremo giù e in poco tempo raggiungeremo casa. (Coris: MON2014_16)

'Kad budu prestali/prestanu da nas traže, vratićemo se dole i za kratko vreme ćemo stići do kuće.'

3 Italijanski anteriorni futur obrađen je u Janićijević (2016a), a ovde iznosimo neke delove tog rada, kao i pojedine primere koji su u njemu navedeni. Sveobuhvatna analiza glagolskih oblika i konstrukcija za izražavanje budućnosti u italijanskom i srpskom jeziku prikazana je u Janićijević (2016b).

4 Referencijalna tačka prema kojoj se anteriorni futur orijentiše može biti određena kako drugom budućom radnjom, tako i priloškom odredbom za vreme. 
(5) Voi ve ne andrete quando avremo finito! (Coris: NARRATRomanzi) 'Vi ćete otići kad budemo završili/završimo!'

Ovakva upotreba anteriornog futura u potpunosti se poklapa s upotrebom srpskog futura II, koji samim tim predstavlja njegov odgovarajući ekvivalent. Poznato je da je u srpskom jeziku perfektivni prezent komutabilan s futurom II svršenih glagola, ${ }^{5}$ tako da je i ovaj glagolski oblik ekvivalent italijanskog anteriornog futura, što se vidi i iz prevoda navedenih italijanskih primera (1)-(5).

Za razliku od anteriornog futura, srpski futur II imašire mogućnosti upotrebeu vremenskoj rečenici jer on može da označi i radnju koja je anteriorna u odnosu na radnju upravne rečenice, kao i radnju koja je istovremena s njom ili posteriorna u odnosu na nju.Kako navode Milošević (1970) i Tanasić (2005), u uspostavljanju različitih vremenskih odnosa, futur II ne deluje samostalno već u kombinaciji sa vremenskim veznikom i vidskim značenjem glagola u upravnoj i zavisnoj rečenici.Odnos anteriornosti uspostavlja se najpre upotrebom svršenog glagola, što je i pravilo uz veznik kad, jer je on semantički neobeležen, dok se uz veznike nakon što, pošto, čim, kojisami po sebi upućuju na značenje anteriornosti, mogu upotrebiti i nesvršeni glagoli.

Osim toga,futur II se javlja i u drugim vrstama zavisnih rečenica, kao što su pogodbene, relativne iporedbene (v. Milošević, 1970; Tanasić, 2005; Piper \& Klajn,2013), u kojima anteriorni futur nije uobičajen.Dok se kod relativnih i poredbenih rečenica odnos anteriornosti uspostavlja upotrebom svršenog glagola, kod pogodbenih rečenica glagolski vid ima manju ulogu, jer je bitan i karakter same rečenice odnosno funkcija uslova (Milošević, 1970: 75; Tanasić, 2005: 449), mada se i u njimaznačenje anteriornosti pretežnoostvaruje upotrebom svršenog vida.Naredni primeri ilustruju upotrebu futura II u pogodbenoj, relativnoj i poredbenoj rečenici.U svim primerimafutur II se može zameniti perfektivnim prezentom, koji dodajemo u zagradi:

5 U srpskom ekvivalentu primera (1) nalazi se dvovidski glagol „razgovarati“, koji je u datoj vremenskoj rečenici svršenog vida; glagoli u primerima (2)-(5) su svršenog vida. 
(6) Ako budete požurili(požurite), stići ćete na vreme. (Kssj: GramabezA.xml)

'Se vi sbrigherete/sbrigate, arriverete in tempo.'

(7) Dakle, ako me budu pozvali (pozovu), svakako u biti na raspolaganju (...) (Kssj: poli071101.txt.)

'Allora, se mi chiameranno/chiamano, sarò certamente a disposizione (...)'

(8) Izbor partnera zavisiće, pre svega, od tehnologije koju bude ponudio (ponudi). (Kssj: poli090305.txt)

'La scelta del partner dipenderà, innanzitutto, dalla tecnologia che offrirà.'

(9) Slaviće onaj ko bude napravio (napravi) manje grešaka. (Kssj: rts091126.txt)

'Festeggerà colui che farà/avrà fatto meno errori.'

(10) A sada postupite tačno onako kako vam budem rekla. (Kssj: DV_ kod.txt).

'E ora faccia esattamente così come Le $\underline{\text { dico/dirò. }}$

(11) (...)biće kako većina bude odlučila (odluči).(Kssj: poli080912.txt) '(...) sarà come decide/deciderà la maggioranza.

Kako se na osnovu prevoda može videti, odgovarajući italijanski ekvivalenti futura II u primeru (6)i (7) s pogodbenom rečenicomsuprost futur i prezent, u primeru (8) prost futur, a u primeru (9) prost futur i anteriorni futur. Prost futur je prikladniji ekvivalent jer je u relativnim rečenicama uobičajeniji od anteriornog futura, koji sekoristikada govornik želida naročito naglasi anteriornost radnje, odnosno svršenost/izvršenost radnje, to jest nastalo stanje koje je okvir, preduslov za vršenje radnje u upravnoj rečenici. U primerima (10) i (11) s poredbenom rečenicom italijanski ekvivalenti futura II mogu biti prezent i prost futur.

Za razliku od futura II, anteriorni futur se može upotrebitii u upravnoj rečenici, gde označavabuduću radnju koja prethodi radnji vremenske rečenice: 
(12) Mia cara mamma, sarò già partita, quando riceverai questa lettera. (Coris: STAMPAPeriodici)

(a) 'Draga moja mama, ja ću već otputovati, kad ti budeš primila/ primiš ovo pismo.'

(b) 'Draga moja mama, dok ti primiš/budeš primila ovo pismo, ja ću (već) otputovati.'

(c) 'Draga moja mama, ja ću (već) otputovati, pre nego što ti budeš primila/primiš ovo pismo.'

Kao što smo već istakli u Janićijević (2016a, 2016b), u ovom slučaju kao srpski ekvivalent italijanskog anteriornog futura u upravnoj rečenici javlja se futur I, dok se u vremenskoj rečenici kao ekvivalenti prostog futura javljaju futur II odnosno perfektivni prezent. Kako je već rečeno, u srpskom jeziku u uspostavljanju vremenskih odnosa u vremenskoj rečenici veliku ulogu imaju glagolski vid i veznik, a pošto su u srpskom oba predikata (i upravne i u zavisne rečenice), svršenog vida a vremenska rečenica je uvedena veznikom $\mathrm{kad}$, sam futur I nije dovoljan da označi anteriornost buduće radnje u odnosu na radnju iskazanu futurom II, te se on mora upotrebitiu kombinaciji s prilogomveć (12a). Bez ovog priloga radnja upravne rečenice protumačila bi se kao posteriorna u odnosu na radnju zavisne. Kao što ilustruju prevodi primera (12), vremenski odnos između radnje upravne rečenice $\mathrm{s}$ anteriornim futurom i zavisne s prostim futurom može se na srpskom izraziti i upotrebom veznika dok (12b), koji uz dva svršenaglagola eksplicitno upućuje na posteriornost radnje vremenske rečenice koju uvodi. ${ }^{6} \mathrm{U}$ tom slučaju prilogveć nije neophodan jer je redosled radnji jasan na osnovu samog veznika i glagolskog vida. Osim veznika dok, u prevodu je moguće upotrebiti i veznik pre nego što (12c), koji u sebi već nosi značenje posteriornosti, tako da i u ovom slučaju prilog već nije neophodan.

6 Odnosi između veznika, glagolskih vremena i glagolskog vida u vremenskoj rečenici detaljno su obrađeni u Antonić (2001). O vremenskoj rečenici u značenju posteriornosti v. i Kovačević (2011), a o upotrebi futura II i perfektivnog prezenta uz veznike pre nego što i dok v. Milošević (1970). 


\section{Prost futur i prezent u italijanskom jeziku - Futur I i perfektivni prezentu srpskom}

U skladu s tendencijama savremenog italijanskog jezika ka resistematizaciji i uprošćavanju složenog glagolskog sistema indikativa (Berruto, 1987; Bozzone Costa, 1991; Berretta,1991, 1992; Bazzanella, 1994; D'Achille, 2003), anteriorni futur se sve višepovlači iz temporalne upotrebe. Njegova upotreba u vremenskoj rečenici polako se ograničava na pisani jezik i formalni registar,dok u svakodnevnom govornom jezikubiva zamenjen prostim futurom, kaoi prezentom i složenimperfektom, čija je futurska upotreba vezanaprvenstveno za neformalni registar. S obzirom na činjenicuda njegovu funkcijuiskazivanja anteriornih budućih radnji polako preuzimaju druga vremena, anteriorni futurse sve više specijalizuje za izražavanje različitih modalnih (epistemičkih) značenja, što je u govornom jeziku gotovo već postala njegovaprimarna funkcija. Na ovu pojavuukazuju i rezultati analize dva različita korpusa govornog jezika, koju su sprovele Bozzone Costa (1991) i Berretta (1994).

Pitanje zamene anteriornog futura prostim futurom $\mathrm{u}$ vremenskoj rečenici nije razmatrano u literaturi o italijanskom jeziku. Samim tim, ni pitanjeeventualnih razlika koje proističu iz upotrebe jednog ili drugog glagolskog oblika nije naučno obrađeno.

I u primerima (2)-(5) $)^{7}$, koje smo gore naveli, anteriorni futur se može zameniti prostim futurom:

$7 \quad$ Samo u primeru (1) anteriorni futur se ne može zameniti prostim futurom.Na osnovu brojnih primera koje smo analizirali, mišljenja smo da je zamena anteriornog futura prostim futurom uslovljena veznikom koji uvodi vremensku rečenicu, kao i akcionalnim obeležjima glagola vezanim prvenstveno za opoziciju durativno-nedurativno i telično-atelično. U svim analiziranim primerima u kojima se anteriorni futur može zameniti prostim futurom upotrebljen je telični glagol. U primerima (1) i (2) vremenska rečenica uvedena je veznikom dopo che 'nakon što', 'pošto', koji najčešće zahteva upotrebu složenog vremena (Bertinetto, 1986: 201). Međutim, dok je uz njega moguće upotrebiti prost futur (primer 11) rezultativnog glagola passare la frontiera 'preći granicu' koji nosi obeležje [+ durativno], [+ telično], uz isti ovaj veznik ne bi bilo moguće upotrebiti prost futur kontinuativnog glagola parlare 'pričati', 'razgovarati' s obeležjima [+ durativno], [- telično]: *D'accordo, mi arrabbierò dopo che parleremo.Pitanje pod kojim je tačno uslovima u vremenskoj rečenici moguća supstitucija anteriornog futura prostim futurom zahteva dodatnu analizu i ostaje otvorena tema za dalja proučavanja. 
(13) Lo (il cellulare) accenda solo dopo che passerà la frontiera. 'Upalite ga (mobilni) tek nakon što budete prešli/pređete granicu.'

(14) Appena guadagnerò abbastanza soldi per venire a Bruxelles, verrò. 'Čim budem zaradio/zaradim dovoljno novca da dođem u Brisel, doći ću.’

(15) Quando smetteranno di cercarci, torneremo giù e in poco tempo raggiungeremo casa.

'Kad budu prestali/prestanuda nas traže, vratićemo se dole i za kratko vreme ćemo stići do kuće.’

(16) Voi ve ne andrete quando finiremo!

'Vi ćete otići kad budemo završili/završimo!'

Kako u primerima (2)-(5), tako i u primerima (13)-(16) i anteriornimfuturom i prostim futurom izražava sebudućaradnja koja prethodi radnji upravne rečenice. Iako su oni ovde manje-više sinonimni, izvesna razlika među njima ipak postoji.Dok se kod upotrebe prostog futura naglasak stavlja isključivo na samu buduću radnju, kod upotrebe anteriornog futura se, u skladu sa njegovim rezultativnim značenjem, naglasak stavlja i na radnju i na rezultat koji iz nje proizilazi. Drugim rečima, anteriornim futurom se označava i da su posledice radnje na kojuupućuje aktuelnei relevantne u trenutku (iz)vršenja druge buduće radnje. Tako se u primeru (2) upotrebom anteriornog futura implicira da će se $u$ vreme vršenja radnje upravne rečenice subjekat nalaziti s druge strane granice, a u primeru (3) da će govornik u trenutku odlaska imati zarađen novac. Rezultativno značenje implicitno je prisutno i u primerima (4) i (5).Rezultativno značenje glagola nije izraženo u primerima (13)-(16).

U italijanskom jeziku se, umesto anteriornog futura, odnosno futura I, može upotrebiti i prezent. Kao što je već napomenuto, takva upotreba prezenta svojstvena je uglavnom neformalnom, kolokvijalnom registru ion senajčešće javlja u kombinaciji s drugim prezentom u upravnoj rečenici, kao što ilustruju sledeći primeri:

(17) Se mi assolvono, appena esco, lo ammazzo. (Coris: MISCVolumi) 'Ako me oslobode optužbe, čimizađem, ubiću ga.' 
(18) Ti chiamo quando torno.(Coris:MON2014_16)

'Zovem te kad se vratim.'

Što se tiče međusobne zamenljivosti futura I i futura II, kritikujući stav K. Milošević $(1970,1982)$ da oni ni u jednom sintaksičkom položaju nisu semantički ekvivalentni, a generalno i celokupnu srbističku i serbokroatističku literaturu, u kojoj se, kako navodi, poricala ekvivalentnost futura I s futurom II(u bilo kom tipu zavisnosložene rečenice), Kovačević (2008) tvrdi da u raznim tipovima zavisnih rečenica ${ }^{8}$ futur I, futur II i perfektivni prezent, pod određenim uslovima, mogu biti relativni sinonimi. Prema mišljenju Kovačevića (2008: 201), njihova ekvivalentnost može se ostvaritiako se neutralizuje subjektova uverenost u izvršenje buduće radnje, odnosno ako se u prvi plan stavi neizvesnost, nesigurnost subjekta u pogledu njenog izvršenja. Što se zavisnih rečenica tiče, prema Kovačeviću,konkurentnost dvaju futura i perfektivnog prezenta, ostvaruje se u: relativnim adnominalnim rečenicama (restriktivnim i nerestriktivnim), odnosnim koncesivnim i načinskim rečenicama, određenim vrstama vremenskih rečenica (uz veznik pre nego što), nekim pogodbenim i koncesivnim, kao i nekim od izričnih zavisnih rečenica, što on ilustrujemnogobrojnim primerima preuzetim najvećim delom iz dnevnih novina, i u nešto manjoj meri iz književnih dela.Međutim, kako je već zapazila M. Golub (2014: 350) u vezi s primerima sa vremenskim rečenicama uz veznik pre nego što i pogodbenim rečenicama, u skoro svim primerima za koje Kovačević navodida futur II, futur I i perfektivni prezent imaju isto značenje, u izvornim primerima nalazi sefutur II ili perfektivni prezent, te, kako ona zaključuje, ukoliko i nije nemoguće da se umesto njih upotrebi futur I, to svakako nije uobičajeno za srpski jezik. Na to bismo samo mogli da dodamo da se i u ostalim vrstama rečenica u izvornim primerimauglavnom javljaju futur II ili perfektivni prezent.

\section{Složeni perfekat u italijanskom jeziku -Perfekat u srpskom}

U skladu sa pravilima o slaganju vremena u italijanskom jeziku, odnosno s njihovom relativnom upotrebom u srpskom, kako italijanski slo-

$8 \quad$ Što se prostih rečenica tiče, po Kovačeviću (2008: 202),ova tri glagolska oblika mogu se upotrebiti kao sinonimi samo uz modalni prilog možda. 
ženi perfekat, tako i srpski perfekat upotrebljavaju se u pojedinim vrstama zavisnih rečenica (pre svega dopunskim, zavisno-upitnim, a italijanski složeni perfekat i u relativnim restriktivnim: v. Vanelli, 1991: 631; Vanelli \& Renzi,1991: 321) da označe radnju koja sledi trenutku govora, a prethodi drugoj budućoj radnji. Sledeći primeri, preuzeti od navedenih autora,jasno ilustruju ovakvu upotrebu italijanskog složenog perfekta i srpskog perfekta:

(19) Domani non ho nessuna intenzione di andare da Piero. Se si arrabbierà, gli dirò che sonoandata dal dottore. (Vanelli \& Renzi, 1991: 321)

'Sutra nemam nameru da idem kod Pjera. Ako se naljuti, reći ću mu da sam išla kod doktora.'

(20) Se pianterai quegli alberi, solo fra vent'anni si saprà quanti hanno attecchito. (Ibid)

'Ako posadiš to drveće, tek za dvadeset godina će se znati koliko ih se primilo.'

(21) Chiederò questo libro a qualcuno. Ma prometto che lo restituirò alla persona che me l'ha prestato. (Ibid)

'Tražiću tu knjigu od nekoga. Ali, obećavam da ću je vratiti onome ko mi je budepozajmio/pozajmi.'

Radnja označena italijanskim složenim perfektom i srpskim perfektom ne odmerava se direktno prema trenutku govora već prema budućoj radnji u upravnoj rečenici. U italijanskom jeziku seu svim rečenicama, osim dopunskoj, umesto složenog perfektamože upotrebitianteriorni futur. I u primerima (20) i (21) on bi mogao da zameni složeni perfekat. Međutim, takva upotreba anteriornog futura je dosta retka jer ovo vreme sadrži i epistemičku dimenziju, koja je u navedenim primerima nepoželjna jer su oni zasnovani na realnim, očekivanim situacijama i okolnostima.Uobičajeniji je složeni perfekat, i u pisanom i u govornom jeziku, upravo kao izraz govornikove namere da uputi na realne i ostvarljive situacije.

Kako se na osnovu prevoda primera (19) i (20)vidi, u srpskom jeziku sejavlja samo perfekat; upotreba futura II u ovim rečenicama nije moguća. U primeru (21) odgovarajući srpski ekvivalenti složenog perfekta su futur II i perfektivni prezent. 
U skladu sa gore navedenim tendencijama savremenog italijanskog jezika, složeni perfekat se sve više javlja i u vremenskim rečenicama, kao zamena za anteriorni futur. Ovakva upotrebazastupljena je pre svega u govornom jeziku, a kao i anteriorni futur, i složeni perfekat ima rezultativno značenje i ukazuje na posledice radnje koju uvodi. Naredni primeri ilustruju ovakvu upotrebu složenog perfekta:

(22) Ti sposerò un minuto dopo che ti sei divorziata. (Coris: NARRATTrRomanzi)

'Oženiću se tobom minut nakon što se razvedeš/ $\underline{\text { budeš razvela.' }}$

(23) Domani partiamo, appena hai finito dal notaio.(Coris: MON2005_07)

'Sutra krećemo čim završiš/budeš završio kod beležnika.'

U srpskom jeziku se u vremenskoj rečenici upotrebljavaju futur II i perfektivni prezent, tako da oni predstavljaju odgovarajuće ekvivalente datog složenog perfekta, s tim što perfektivni prezent vernije dočarava registar u kome je složeni perfekat upotrebljen, jer je i on u srpskom jeziku učestaliji i uobičajeniji od futura II (v. Milošević, 1970; Tanasić, 2005).

\section{Konjunktiv perfekta u italijanskom jeziku}

U italijanskom jezikui konjunktiv perfekta može označavatianteriorne buduće radnje u vremenskoj rečenici, kao što ilustruju sledeći primeri:

(24) Gli parlerò solo dopo che mi abbia chiesto scusa. (Patota, 2006: 281) 'Razgovaraću s njim tek nakon što mi se bude izvinio/izvini.'

(25) Una volta che sia partito, chi se ne ricorderà più? (Sabatini \& Coletti, 2006)

'Kada bude otišao/ode, ko će ga se više sećati?'

Radnja označena konjunktivom perfekta ima određenu dozu neizvesnosti i hipotetičnosti. Ona se prikazuje kao apsolutni uslov za vršenje radnje upravne rečenice, i to kao apstraktan, eventualno ostvarljiv uslov. Iako je gramatike navode, ovakva upotreba konjunktiva perfektaretko se ostvaruje u govornom jeziku, isvojstvena je pisanom jeziku i formalnom registru. 
Poštose konjunktiv perfekta javlja u vremenskoj rečenici, njegovi odgovarajući srpski ekvivalenti su futur II,odnosno perfektivni prezent.

\section{Zaključak}

Nakon sagledavanja i poređenjaglagolskih vremena kojima se mogu izraziti anteriorne buduće radnje u italijanskom i srpskom jeziku, opšti zaključak koji se može izvesti jeste da se između ova dva jezika javljaju kako sličnosti, tako i brojne razlike.

Što se sličnosti tiče, one se ogledaju u činjenici da oba jezika u svom glagolskom sistemu poseduju oblik čija je osnovna funkcija označavanje anteriorne buduće radnje (anteriorni futur u italijanskom, futur II u srpskom), kao i da raspolažu drugimoblicima koji, u odgovarajućim sintaksičko-semantičkim okolnostima, mogu izražavati anteriornu budućnost.

Osnovna razlikaispoljava se u činjenici da mnoga,formalno ista sredstva, imaju potpuno ili delimično različitu sintaksičku distribuciju, što, uz njihovo osnovno vremensko značenje, utiče na (ne)mogućnost da ona izraze anteriornu buduću radnju.Delimične razlike prisutne su kod sintaksičke distribucije italijanskog anteriornog futura i srpskog futura II. Dok se italijanski anteriorni futur javlja prevashodno u vremenskoj rečenici, srpski futur II može izražavati anteriorne buduće radnje i u drugim vrstama zavisnih rečenica. Potpune razlike u sintaksičkoj distribuciji javljaju se između italijanskog prostog futura i složenog perfekta s jedne strane i srpskog futura I i perfekta s druge. Dokitalijanski prost futur i složeni perfekatmogu alternirati s anteriornim futurom u vremenskoj rečenici, srpski futur I i perfekatne mogu biti zamena za futur II u vremenskoj rečenici. Isto tako,italijanski prost futur može označavati anteriornu buduću radnju u raznim vrstama zavisnih rečenica, u kojima se u srpskom po pravilu upotrebljavaju futur II i perfektivni prezent.

Razlike između italijanskog i srpskogjezika ogledaju se i u broju sredstava kojima se može obeležiti anteriorna buduća radnja. Naime, u poređenju sa srpskim, italijanski ima za nijansu veći brojraspoloživih oblika za obeležavanje anteriorne buduće radnjejer i konjunktiv perfekta, u odgovarajućim sintaksičko-semantičkim okolnostima, može označavatiradnju koja je posteriorna u odnosu na trenutak govora, a anteriorna u odnosu na drugu buduću radnju. 
Na kraju treba reći da je u ovom radu dat opis i poređenje mogućih sredstava za obeležavanje anteriorne buduće radnje onako kako ih definišu gramatike italijanskog i srpskog jezika. Međutim, nisu svioblici,koje gramatike dvaju jezika navode, podjednako zastupljeni u upotrebi. Kao što jenapomenuto, iako je u italijanskom jeziku anteriorni futur po definicijiosnovni oblik za iskazivanje anteriornih budućih radnji, on se u savremenom italijanskom jeziku relativno retko koristi, iumesto njegauobičajenijijeprost futur,a u određenim okolnostima i prezent i složeni perfekat, o čemu svedoče i podaci u literaturi o italijanskom jeziku (Berruto, 1987; Bozzone Costa, 1991; Berretta, 1992; i dr.). Sličan je slučaj i sa futurom II u srpskom jeziku; poznato je, a u literaturi takođe zabeleženo, da je umesto njega uobičajeniji perfektivni prezent (Milošević, 1970; Tanasić, 2005). Osim toga, kako je već rečeno, iako italijanski konjunktiv perfekta teorijski ima mogućnost da označi anteriornu buduću radnju, on se u toj funkciji retko ostvaruje. I najzad, što se italijanskog složenog perfekta i srpskog perfekta tiče, oni mogu biti markeri za anteriornu buduću radnju samo u određenim, dosta ograničenim, sintaksičko-semantičkim okolnostima.

\section{LITERATURA}

Antonić, I. (2001). Vremenska rečenica. Sremski Karlovci/Novi Sad: Izdavačka knjižarnica Zorana Stojanovića.

Bazzanella, C. (1994). Le facce del parlare. Firenze: La Nuova Italia.

Berretta, M. (1991). Parliamo del nostro futuro. Italiano e Oltre, 6/3, 135-140.

Berretta, M. (1992). Sul sistema di tempo, aspetto e modo nell'italiano contemporaneo. In B. Moretti, D. Petrini \& S. Bianconi (a cura di), SLI 25.Linee di tendenza dell'italiano contemporaneo (pp. 135-153). Roma: Bulzoni Editore.

Berretta, M. (1994). Il futuro nella varietà nativa colloquiale e nelle varietà di apprendimento. Zeitschrift für Romanische Philologie, 110/1-2, 1-36.

Berruto, G. (1987). Sociolinguistica dell'italiano contemporaneo. Roma: La Nuova Italia Scientifica.

Bertinetto, P. M. (1986). Tempo, aspetto e azione nel verbo italiano. Il sistema dell'indicativo. Firenze: Accademia della Crusca.

Bozzone Costa, R. (1991). L'espressione della modalità non-fattuale nel parlato colloquiale (con particolare riferimento agli usi del futuro). Quaderni del Dipartimento di Linguistica e Letterature Comparate, 7, 25-73. 
CORIS - Corpus dell'italiano scritto, Facoltà di Lettere e Filosofia, Università di Bologna, http://www.corpora.dslo.unibo.it/coris_ita.html.

D'Achille, P. (2003). L'italiano contemporaneo. Bologna: Il Mulino.

Korpus savremenog srpskog jezika (verzija SrpKor2013) Copyright Grupa za jezičke tehnologije Univerziteta u Beogradu,http://www.korpus.matf.bg.ac. rs. (autori verzije SrpKor2013: Duško Vitas i Miloš Utvić).

Golub, M. (2014). Anteriorna upotreba budućih vremena u latinskom i njihovi ekvivalenti u srpskom jeziku. U S. Gudurić \& M. Stefanović (prir.), Jezici i kulture u vremenu i prostoru,IV/1 (pp. 349-356). Novi Sad: Filozofski fakultet u Novom Sadu.

Janićijević, N. (2016a). Italijanski anteriorni futur i njegovi srpski ekvivalenti. U A. Vraneš \& Lj. Marković (prir.), Kulture u prevodu, 2 (pp. 247-260). Beograd: Filološki fakultet.

Janićijević, N. (2016b).Iskazivanje budućnosti glagolskim oblicima i konstrukcijama u italijanskom i srpskom jeziku(neobjavljena doktorska disertacija). Filološki fakultet, Beograd.

Kovačević, M. (2008). Konkurentnost dvaju futura i perfektivnog prezenta u savremenom srpskom jeziku. Zbornik Matice srpske za slavistiku, 73, 195211.

Kovačević, M. (2011). Gramatička pitanja srpskoga jezika. Beograd: Jasen.

Milošević, K. (1970). Futur II i sinonimski oblici u savremenom srpskohrvatskom književnom jeziku. Sarajevo: Akademija nauka i umjetnosti Bosne i Hercegovine.

Milošević, K. (1982). Obeležavanje budućnosti u srpskohrvatskom jeziku. Književni jezik, 11/1, 1-12.

Patota, G. (2006). Grammatica di riferimento dell'italiano contemporaneo. Novara: Garzanti Linguistica.

Piper, P. \& I. Klajn (2013). Normativna gramatika srpskog jezika. Novi Sad: Matica srpska.

Sabatini, F. \& V. Coletti (2006). Dizionario della lingua italiana. Milano: Rizzoli Larousse.

Tanasić, S. (2005). Sintaksa glagola. UP. Piper et al., Sintaksa savremenoga srpskog jezika: prosta rečenica (pp. 345-476). Beograd: Institut za srpski jezik SANU/Beogradska knjiga/Matica srpska.

Vanelli, L. (1991). La concordanza dei Tempi. In L. Renzi \& G. Salvi (a cura di), Grande grammatica italiana di consultazione. Volume II: I sintagmi verbale, aggettivale, avverbiale. La subordinazione(pp.611-632.) Bologna: Il Mulino. 
Vanelli, L. \& L. Renzi (1991). La deissi. In L. Renzi, G. Salvi \& A. Cardinaletti (a cura di), Grande grammatica italiana di consultazione. Volume III: Tipi di frasi, deissi, formazione delle parole(pp. 261-375). Bologna: Il Mulino.

\title{
Nataša L. Janičijević
}

\section{THE EXPRESSION OF ANTERIOR FUTURE TIME SITUATIONS IN ITALIAN AND SERBIAN}

\begin{abstract}
Summary
The paper provides a contrastive analysis of the Italian and Serbian tenses which can be used to express a future event that will take place prior to another future event. Its aim is to determine the differences and similarities between the various tenses used in the two languages for marking anteriority in the future, as well as to establish to what extent the two languages display differences and similarities in regard to the way anteriority in the future is expressed.

Key words: Italian, Serbian, anterior future tense, simple future tense, future I tense, future II tense, perfective present, compound perfect, perfect tense, equivalents.
\end{abstract}

